\title{
Studies on Mechanical, Thermal properties and Characterization of Nanocomposites of Nylon-6 - Thermoplastics Poly Urethane Rubber [TPUR] blend
}

\author{
Ceasar GunaSingh, S.Soundararajan*and K. Palanivelu \\ (Dept of Plastics Technology / Central Institute of Plastics Engineering and Technology, Chennai-600032 \\ India)
}

\begin{abstract}
Nylon6 is having low impact strength. To improve the impact strength nylon6 is modified with TPUR and nanoclays. Nylon-6 was melt mixed with nanoclay [1\%, 3\%, \& 5\%] and then melt blended with TPUR [Thermoplastic Poly Urethane Rubber] [15\%] using a co-rotating twin screw extruder. Nanoclays used are Cloisite $\mathrm{Na}^{+}$[sodium montmorillonite][MMT] and Cloisite 30B [organically modified montmorillonite] [O-MMT]. Test specimens were made by using an injection molding machine for mechanical and thermal properties evaluation. Generally, higher tensile Strength, flexural strength and modulus were obtained with Cloisite $30 \mathrm{~B}$ than that of Cloisite $\mathrm{Na}^{+}$since Cloisite $30 \mathrm{~B}$ has more compatibility due to -OH groups present in the organic modifier. For 5\% formulations, the flexural modulus is higher, and impact strength is lower. $1 \%$ cloisite 30B shows highest impact strength [33\% Higher]. The Tensile modulus is 16\% higher with 5\% Cloisite 30B. The elongation at break was lowered very much with cloisite $30 B$ from $185 \%$ to $4 \%$. The SEM micro photographs shows that the TPUR and Nylon6 are compatible and also in presence of the both type of nanofillers. DSC also confirms that nylon6-TPUR and nanocompsites with $30 B$ are compatible. The XRD shows the intercalation of cloisite $30 \mathrm{~B}$ of clay at $1 \%$ and $3 \%$. But at $5 \%$ clay incorporation it is not much intercalated. The thermal stability were improved for both types of nano composites as determined by TGA. The flammabililty test shows that cloisite $\mathrm{Na}^{+}$filled composites were having UL $94 \mathrm{~V} 2$; but, Cloisite $30 \mathrm{~B}$ filled nanocomposites were not meeting the UL94 V/HB Standard.
\end{abstract}

Key Words: Nylon6, TPUR, Nanoclays, Mechanical \& Thermal properties.

\section{Introduction}

Polymer nanocomposites based on Mont Morillonite[MMT] have been successfully prepared previously with improved stiffness and strength of polymers. The extent of property of improvement depends on many factors such as aspect ratio of the filler, extent of dispersion and adhesion and at the filler matrix interface [1] Mica based phyllosilicates such as mont morillonite has generated great deal of interest. Nano clays are a form of high purity aluminium silicate mineral derived from MMT which have a sheet or plate type structure and the layers are about $\mathrm{I} 0 \mathrm{~nm}$ [ Nano meter] thick with plate dia 100-500 $\mathrm{nm}$. A surface treatment confers an affinity between the MMT and the polymer choice and also expands the gaps between the plates by as much as six times.

Inorganic materials do not have good interaction with organic polymer to achieve good dispersion and adhesion, hence requires surface treatment of clays for good dispersion [2]. Mont morillonite clays have high aspect ratio with unique intercalation / exfoliation characteristics. In order to achieve good intercalation and exfoliation mont morillonite clays are organically modified to balance the net negative charge of aluminium / magnesium silicate layers exchanged with organic molecules with cation groups e.g. alkyl ammonium ions to produce an organoclay [1]. The hydroxyl groups and carboxyl on quarternary ammonium provides better binding energy of the MMT with the polymers [3]. Improved performance of nanocomposites is usually related to the large interface between inorganic fillers and organic matrix even at lower filler [1-5\%] loading [4] than conventional fillers [30-40\%]

Due to their production of lightweight polymer materials with toughness, fire retardant properties, easy processing, increased temperature resistance [HDT] and improved barrier properties they are widely useful in automotive and packaging applications Automotive applications have been the biggest take up of nano plastics so far car trims, and panels which display greater tensile strength, impact strength and scratch resistance and engine parts gain higher HDT. Polyamides, Polypropylene, Polyesters and TPUR have been studied with nano clays and are useful in automotive application due to lighter weight

Incorporating organo clay into polymer matrices has been known for 5-10 years. The direct melt compounding in a twin screw extruder is recognized as an attractive way to produce polymer nanocomposites. Hence, till date it has been successful in many plastics like Nylon-6 [ 5 ,6,7], Nylon-66 [7], Nylon-12[8], 
PET [9], PBT[10], PC[11], PC/ABS[12], Nylon-6/ABS[13], PP[14], PMMA[15],Thermo plastic Poly Urethanes Rubber [TPUR][16] and Epoxy[17,18,19].

Nylon-6/clay nanocomposites are usually more brittle than pure nylon-6, although dramatic improvement is observed in modulus, strength and heat resistance [6]. Some functional elastomers having good compatibility with nylon-6 such as maleic anhydride grafted ethylene propylene elastomer [EPR-graft MA] could be used to improve the toughness of nylon-6/clay nanocomposites [20]. Also Butadiene styrene vinyl pyridine fully vulcanized powdered rubber has good dispersion in nylon-6 due to it's good compatibility in nylon-6 [21]. Also Maleic anhydride graft polyethylene-octene elastomer was reported [22]. The Toughness and stiffness of nylon- 6 unmodified nanoclays was improved by acrylate rubbers [23]

In the present work TPUR has been used as rubber phase for nylon- 6 modification and their nanocomposites with sodium Mont morillonite and organically modified mont morillonite are discussed.

Nylon-6 has higher water absorption, lower electrical properties and good impact strength. TPUR [Thermoplastic polyurethane rubber] has lower water absorption [1/6 of nylon] [24] and higher electrical properties and better impact strength Both nylon and TPUR have lower melt viscosity and good process ability and similar chemical resistance. TPUR has excellent resistance to oxidation with ozone and oxygen which is lacking in conventional elastomers such as natural rubber or synthetic poly isoprene, poly butadiene, styrene butadiene rubber $[\mathrm{SBR}]$

The Polymer alloys and blends [PAB's] have been utilized in the plastics industries because of their unique and combination of characteristics. The PAB's provide improvement in impact strength, chemical resistance, flame resistance, heat distortion temperature[HDT] etc., and also lower cost [optimum] depending upon the type of the polymeric materials used in the PAB's. Hence many plastics alloys blend's are commercially available. We have reported the blends of nylon-6 with TPUR in different proportions [25]

The nylon 6 - TPUR [85:15 wt \%] blend will have optimum mechanical properties with better impact strength, lower water absorption and good electrical insulation properties. However the elastic modulus will be lowered, if nano filler is used [1\%, $3 \%$ \& 5\%] the modulus will be improved along with good toughness. Hence, in this present study, our interest is to know the effect of nanofiller montmorillonite on the mechanical and thermal properties of nylon-6 TPUR blend [85:15\%].

\section{Experimental}

2.1 Materials

The Nylon- 6 used in this work AKULON ${ }^{\circledR}$ K222D [DSM], TPUR was DESMOPAN ${ }^{\circledR} 345$ [BAYER]. In the TPUR, the base raw material is of Butane Diol for polyureathane polymerization, along with polyols and HMDI [Hexa Methylene Di Isocyante] for making hard segments and soft segments respectively for making TPUR. The nano fillers used are sodium mont-morillonite [CLOISITE ${ }^{\circledR} \mathrm{Na}^{+}$] and organically modified mont-morillonite [CLOISITE ${ }^{\circledR} 30 \mathrm{~B}$ ] [Southern clay products Inc. USA].Nanoclays have high surface area and high purity [98-99\%]. In the cloisite 30B it is surface modified and in the cloisite the surface is not modified. Various cloisite structures \& data are given in the literature of Southern Clay Products [Web site: WWW.Southern Clay Products.com] USA. And also in the literature Ref [26], various O-MMT nanoclay's structures like cloisite 30B, 20A, 25A, 93A are given.

The unmodified Cloisite, [natural montmorillonite] has higher thermal stability upto $600{ }^{\circ} \mathrm{C}$ [27]. S.g. $2.86 \mathrm{gm} / \mathrm{cc}$, Moisture content $<=2 \%$, particle Size: $<=2 \mu$ about $10 \%,<=6 \mu$ about $50 \%$, and $<=13 \mu$ about $40 \%$.

The organically modified clay [O-MMT] Cloisite 30B contains the organic modifier Methyl Tallow, bis 2 hydroxyl, quaternary ammonium products, 90 meq. with functional groups like - OH. S.g $1.98 \mathrm{gm} / \mathrm{cc}$, Moisture content, $<=2 \%$, particle Size: $2 \mu$ about $10 \%,<=6 \mu$ about $50 \%$ and $<=13 \mu$ about $40 \%$

\subsection{Twin screw compounding and Test specimen preparation}

Nylon-6 was dried at $80^{\circ} \mathrm{C}$ in an air circulated oven for $6 \mathrm{hrs}$ before compounding. TPUR was dried at $110^{\circ} \mathrm{C}$ for $6 \mathrm{hrs}$ to remove the moisture due to hygroscopic nature of the nylon 6 and TPUR. Cloisite and Cloisite ${ }^{\circledR} 30 \mathrm{~B}$ were dried for $4 \mathrm{hrs}$ in the oven at $80^{\circ} \mathrm{C}$ to remove moisture.

The direct melt blending was carried out in a co-rotating twin screw extruder [Berstorrf, Model ZE 25, FRG] Twin screw extruder Size: L/D ratio is 40:1, ram dia $25 \mathrm{~mm}$, Screw RPM 450[max], Capacity 10-20 $\mathrm{Kg}$ / hour. Two methods were examined. In the first method, nylon-6, TPUR \& filler were bag mixed and then extruded. In the second method, TPUR was introduced in the sixth zone [vent zone] using an additional hopper. The nylon-6 + nano clay were fed in the main hopper, partially melted,and the TPUR was introduced in the sixth zone. This second method gave better results than first method. PA6 can be processed at $235^{\circ} \mathrm{C}$ effectively, but TPUR could not be Compounded [and processed] at that temperature because the residence time is too long and TPUR will degrade and foaming will result during compounding. In the second procedure the residence time was reduced to half of that of nylon- 6 and was about a minute and the materials are not foaming. 
The nylon6/TPUR blend composition was $85 / 15$ by wt. $\%$. Clay was added in the ratio $1 \%, 3 \%$, and $5 \%$ by weight. The compounding temperature was in the range of $190^{\circ} \mathrm{C}-230^{\circ} \mathrm{C}$ and screw rpm was $150-200$. The extruded strands were passed through a water bath and then pelletized.

Zone wise Temperatures are given below.

$\begin{array}{cccccccccc}\text { Zones } & 2 & 3 & 4 & 5 & 6 & 7 & 8 & 9 & 10 \text { [Die] } \\ \text { Temp }\left[{ }^{\circ} \mathrm{C}\right] 190 & 210 & 220 & 225 & 230 & 230 & 235 & 235 & 230\end{array}$

The nano blends were further dried at $110^{\circ} \mathrm{C}$ before injection molding the test specimens for mechanical and thermal properties. SP 130 windsor Injection molding machine was used for the test specimen preparation. The process temperature range was $190-240{ }^{\circ} \mathrm{C}$ [Zones 1-5: 190, 220, 235, 235, 240 [nozzle]] and the injection pressure was $75 \mathrm{MPa}$. For TPUR the temperature in barrel is $240{ }^{\circ} \mathrm{C}$ that too in the nozzle zone only. Also the Number of zones are only 5 which is less than that of twin screw extruder which have 9 zones and long screw length. Hence barrel life / residence time is less. Hence TPUR rubber was not degraded and no colour change was taken place. But, after little long time TPUR may degrade and foam the test specimens.

\subsection{Testing and Characterization}

Tensile properties evaluation [ASTM D 638] was carried out on a UTM [universal testing machine] SHIMADOZU 50KN Shimadzu Corp., Tokyo. The flexural properties were performed as per ASTM 790 with an UTM Lloyd LR 100k U.K. The Rockwell hardness was carried out as per ASTM D785 using digital hardness tester RASN-E, FIL-INDIA. The notch impact strength [ASTM D 256] was performed using ATS FAAR impact tester, FRG, at room temperature. Fractured surfaces of the notched impact test specimen were studied using SEM [JEOL 200M]. X-ray diffraction studies were carried out on PAN Anatica equipment. DSC/ TGA were done using Perkin Elmer Pyris 1 TA instrument. TGA was done with $100 \mathrm{mg}$ sample with heating rate $20^{\circ} \mathrm{C} / \mathrm{min}$ in air atmosphere for all samples. DSC was done using at $10 \mathrm{deg} \mathrm{C} / \mathrm{min}$. Flammability test was carried out as per UL 94 Vertical burning standard.

\section{Results and discussion}

\subsection{Mechanical Properties}

\subsubsection{Tensile Properties.}

As Nano clay concentration were increasing, the tensile strength \& tensile modulus were increasing [Table1 \& 2 ]. In the case of Cloisit $\mathrm{Na}^{+}$, the $5 \%$ formulation has higher the tensile strength [Figure1] and modulus. In the case of Cloisite 30B, the 5\% formulation has higher tensile strength and modulus [Table1] the elongation at break was decreasing in both cases but not brittle except for $5 \%$ cloisite 30B filled which has Eb as $4.14 \%$. i.e Only for $5 \%$ closite $30 \mathrm{~B}$, the elongation at break[Eb] is lowered. For other formulations the $\mathrm{Eb}$ are more than $39 \%$. Generally higher tensile modulus were obtained with Cloisite $30 \mathrm{~B}$ than that of Cloisite $\mathrm{Na}^{+}$since Cloisite 30B has more compatibilty due to the polar interaction of the - $\mathrm{OH}$ groups present in the organic modifier.

Table 1 Tensile Properties of PA6 + TPUR + Cloisite 30B

\begin{tabular}{|c|c|c|c|c|}
\hline Name & $\begin{array}{c}\text { Max_Force } \\
\text { kgf }\end{array}$ & $\begin{array}{c}\text { Max_Stress } \\
\text { Kgf/cm }\end{array}$ & Break_strain \% & $\begin{array}{c}\text { Elastic } \\
\text { Modulus } \\
\text { Kgf/cm }^{2}\end{array}$ \\
\hline PA6 & 245 & 600 & 29 & 21695 \\
\hline PA6+TPUR [85:15\%] & 158 & 454 & 185 & 15107 \\
\hline PA6+TPUR+Cloisite 30B 1\% & 195 & 468 & 71.9 & 14294 \\
\hline PA6+TPUR+Cloisite 30B 3\% & 205 & 496 & 39 & 15133 \\
PA6+TPUR+Cloisite 30B 5\% & 264 & 636 & 4.1 & 17585 \\
\hline
\end{tabular}

Table 2 Tensile Properties of PA6+ TPUR+Cloisite Na+

\begin{tabular}{|c|c|c|c|c|}
\hline Name & Max_Force kgf & $\begin{array}{c}\text { Max_Stress } \\
\text { Kgf/cm2 }\end{array}$ & Break_strain \% & $\begin{array}{c}\text { Elastic Modulus } \\
\text { Kgf/cm2 }\end{array}$ \\
\hline $\begin{array}{c}\text { PA6+TPUR+Cloisite Na+ } \\
1 \%\end{array}$ & 192.0 & 461 & 79 & 8336 \\
\hline $\begin{array}{c}\text { PA6+TPUR+Cloisite Na+ } \\
\text { 3\% }\end{array}$ & 193.8 & 466 & 76 & 11561 \\
\hline $\begin{array}{c}\text { PA6+TPUR+Cloisite Na+ } \\
5 \%\end{array}$ & 217.1 & 522 & 52 & 11617 \\
\hline
\end{tabular}




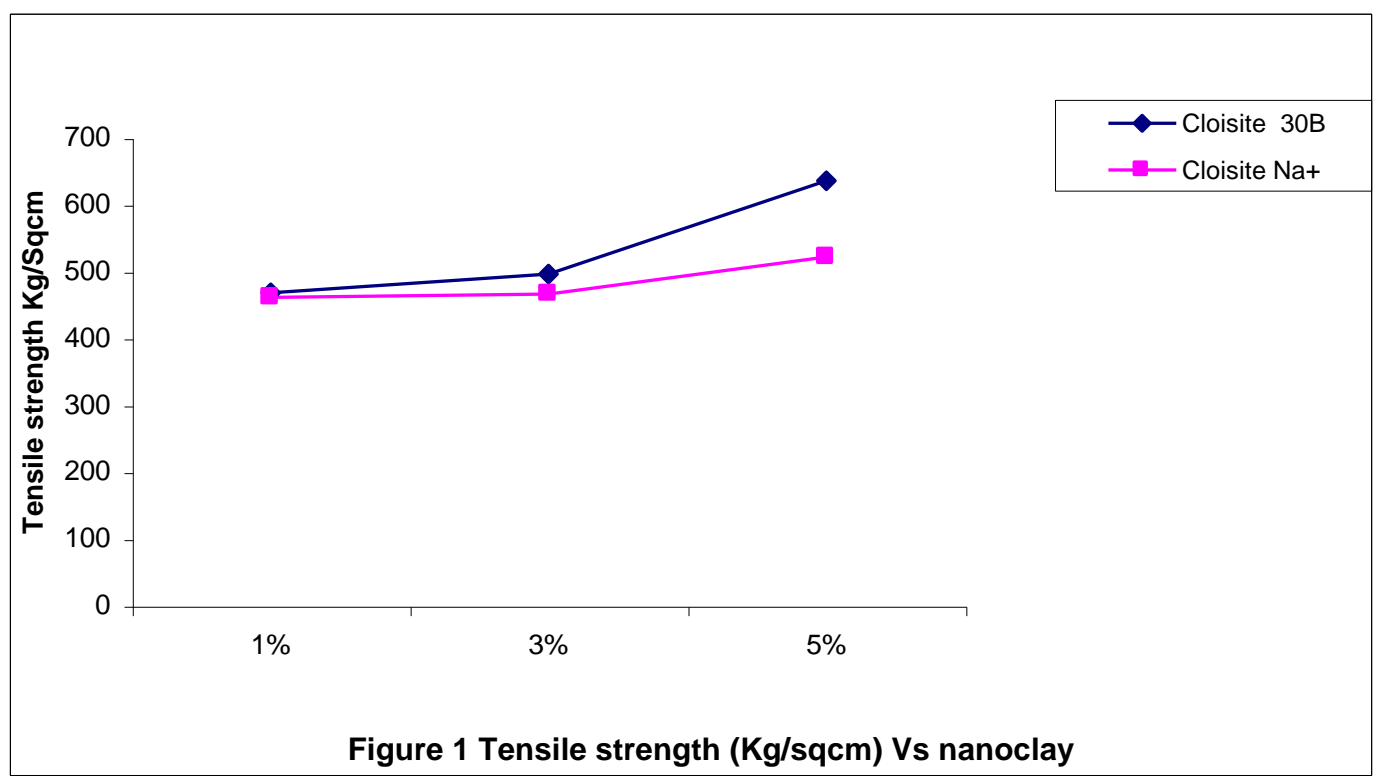

\subsubsection{Flexural Properties \& hardness.}

The flexural strength and modulus [Fig 2] were increasing as the clay concentration was increasing. The rigidity was increasing hence the above trend was obtained. The results were shown in the Table 3 . Higher flexural modulus were obtained in the case of Cloisite 30B than that of closite $\mathrm{Na}^{+}$. Similarly the hardness was increasing in both types of nanocomposites.

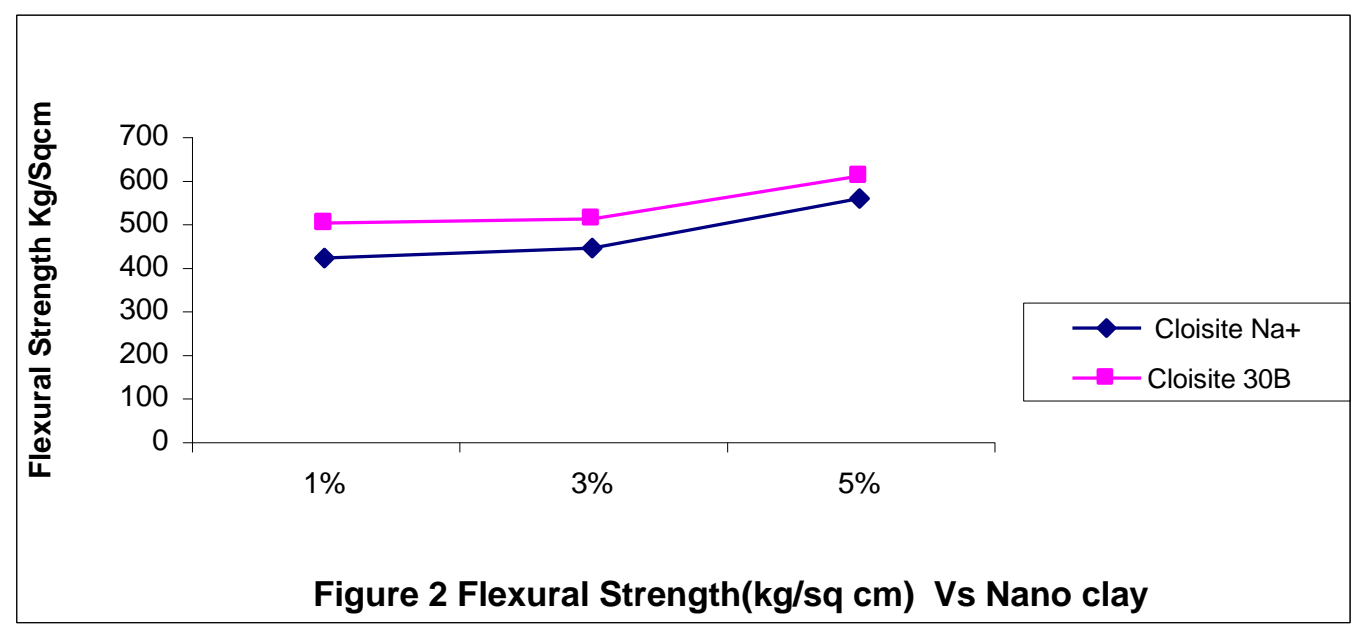

Table 3 : Flexural properties and Hardness of PA6 + TPUR with cloisiteNa+ and cloisite 30B

\begin{tabular}{|c|c|c|c|}
\hline Name & $\begin{array}{c}\text { Flexural strength } \\
\mathbf{K g} / \mathbf{c m}^{2}\end{array}$ & $\begin{array}{c}\text { Flexural modulus } \\
\mathbf{K g} / \mathbf{c m}^{2}\end{array}$ & Rockwell hardness \\
\hline Cloisite Na+ & & & \\
\hline $1 \%$ & 420 & 11800 & 75 \\
\hline $3 \%$ & 443 & 12666 & 87 \\
\hline $5 \%$ & 557 & 14900 & 81 \\
\hline Cloisite 30B & & & 85 \\
\hline $1 \%$ & 500 & 14433 & 95 \\
\hline $3 \%$ & 510 & 14800 & \\
\hline $5 \%$ & 608 & 18800 & \\
\hline
\end{tabular}




\subsubsection{Impact properties}

The Nylon6-TPUR [85:15wt \%] was in good compatibility due to the polar functional groups present in these polymers. The izod impact strength of nylon was improved from $4.50 \mathrm{Kg}-\mathrm{cm} / \mathrm{cm}$ to $11.41 \mathrm{Kg}-\mathrm{cm} / \mathrm{cm}$ when TPUR was added. In the case of Cloisite $\mathrm{Na}^{+}$, due to the nano filler intercalation and toughening notched izod impact strength was increased for $1 \%$ and $3 \%$ and then lowered for $5 \%$ due to more rigidity [Table 4]. In the case of Cloisite 30B the impact was improved for $1 \%$ due to Intercalation and toughening and also due to the-OH functional groups interaction with both amide groups and isocyanate groups; but lowered for 3\% \& 5\% since more interaction leads to higher rigidity and hence hardness and flexural modulus were higher and hence impact strength were little lowered [Table 4] [Fig3].

Table 4 Izod impact strength values $[\mathrm{Kg}-\mathrm{cm} / \mathrm{cm}]$ of Nylon6/TPUR Blend with Nanofiller

\begin{tabular}{|c|c|c|}
\hline \multicolumn{3}{|c|}{ Nylon6/TPUR Blend with Nanofiller } \\
\hline Sample Name & Cloisite Na+ & Cloisite 30B \\
\hline $0 \%$ & 11.41 & 11.41 \\
\hline $1 \%$ & 12.14 & 15.19 \\
\hline $3 \%$ & 14.43 & 10.86 \\
\hline $5 \%$ & 12.39 & 10.82 \\
\hline
\end{tabular}

Nylon-6: $4.50 \mathrm{Kg}-\mathrm{cm} / \mathrm{cm}$

Also, these values are higher than that of nylon6. Hence, super tough materials were obtained with optimum mechanical properties. The Impact strength was increased, in presence of nanoclay due to fine dispersion and leads to intercalation and toughening. i.e. When tensile strength and flexural strength \& flexural modulus and Hardness were increased even at low filler loading about 1-3\% with nanoclay the impact strength values are higher.

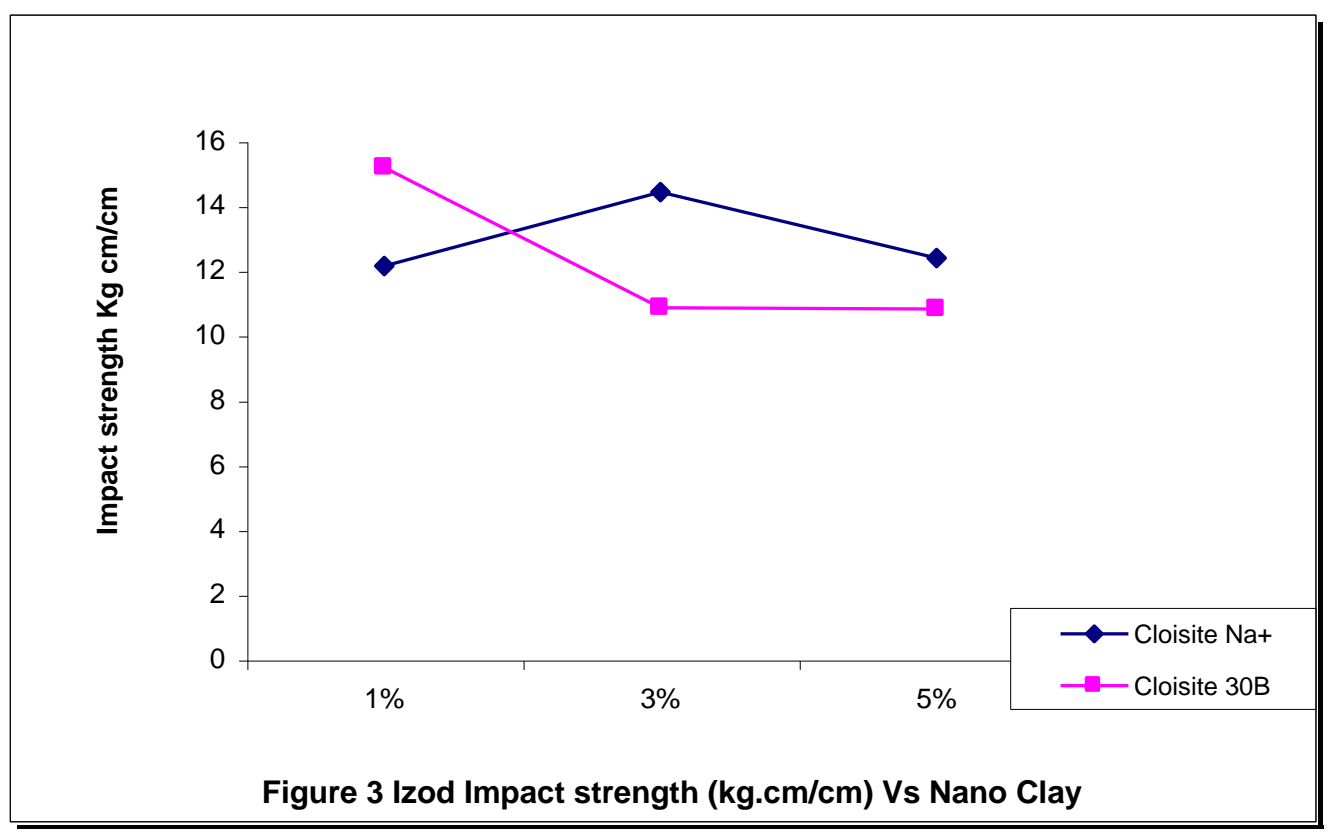

When tensile strength \& flexural strength are increasing, the impact strength should be decreasing with conventional fillers like Calcium Carbonate. But in the case of nanoclays, due to intercalation, toughening takes place, hence even though the tensile strength, flexural strength \& flexural modulus and hardness were increasing, the impact strength are not lowered much. So, It is higher for $1 \% 30 \mathrm{~B}$ clay, and $1 \%, 3 \%$ and $5 \% \mathbf{~ N a}^{+}$ clay. Only with 3\% and 5\% 30B Clay due to much hardness and flexural modulus, the impact strength was slightly little lower than that of Nylon6-TPUR [85:15\%]. This is due interaction of polar groups like OH groups of 30B nanoclay modifier with Nylon6 / TPUR functional groups like $\mathrm{COOH}, \mathrm{OH}$. Impact strength was decreasing along with increasing of flexural \& Tensile strength because of clay intercalation. It was reported in Nylon 12, Impact strength decreased linearly by about $25 \%$ as the clay loading increased [up to 5 wt $\%$ ], indicating an embrittlement due to clay addition. The embrittling effect may be due to the weak interfacial adhesion between the clay platelets and the polymer matrix [28] the maximum toughness at a clay conc. of $5 \mathrm{wt} \%$ is also reported for Nylon6-PS blends [29]. Ductility tends to reduced at higher filler loading [30]. Hence impact strength decreases. 
3.2 Morphology [SEM, DSC AND X-RAY Diffraction]

3.2.1 SEM [Scanning Electron Microscopy]

The SEM microphotograph shows good compatibility of the TPUR with Nylon 6 Fig [4] and of both cloisite $\mathrm{Na}^{+}$and 30B at all concentrations in Nylon6-TPUR [Fig 4a-5b]. At 5\% level the nanofiller may be saturated. In the

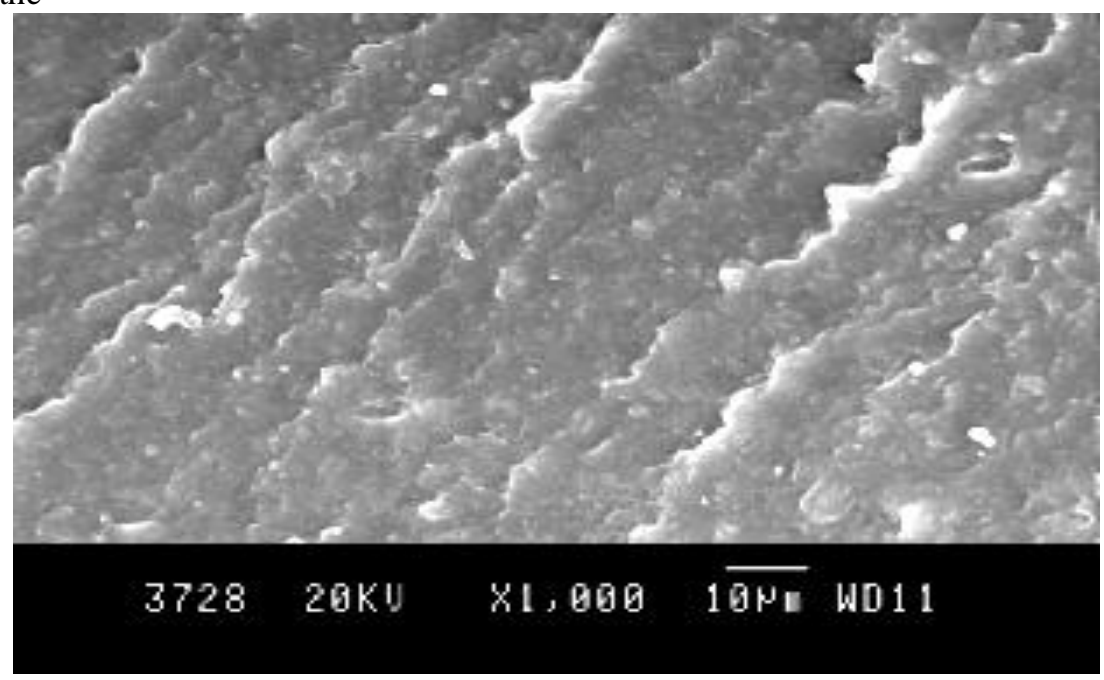

Figure 4 SEM of PA6 + TPUR

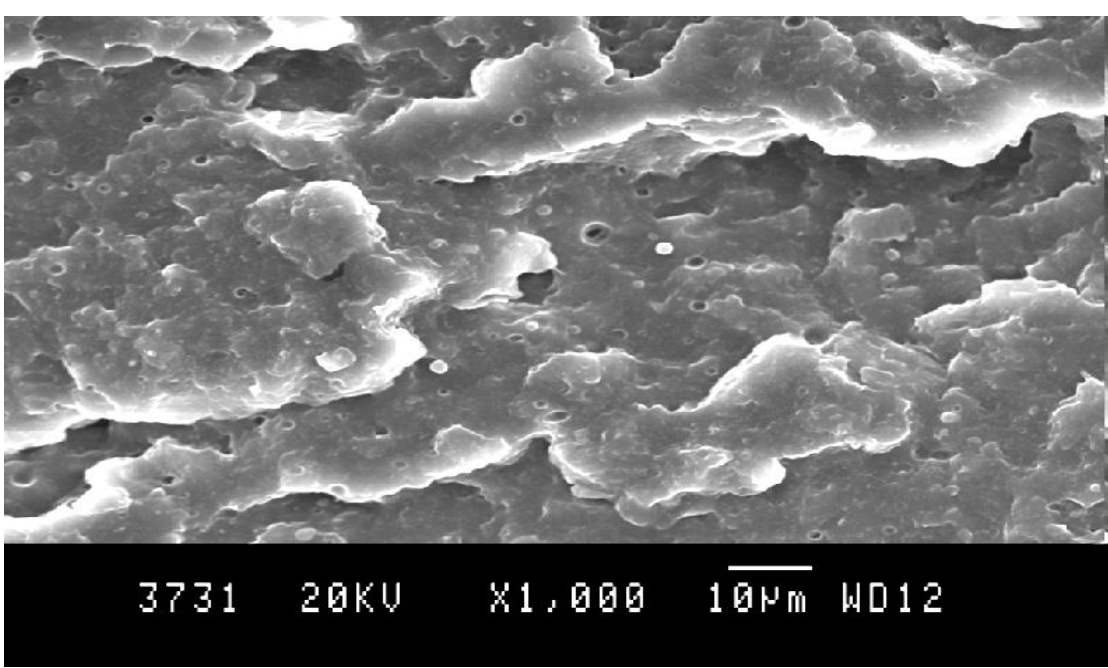

Figure 4a SEM of PA6 + TPU with 3\% CLOISITE N

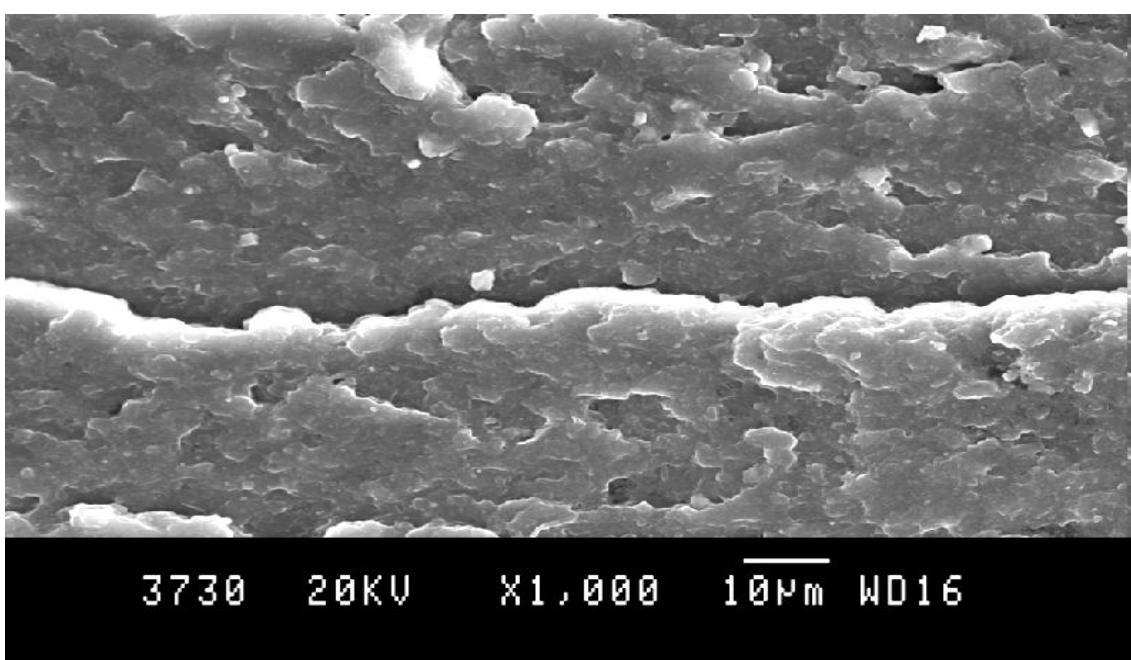

Figure 4b SEM of PA6 + TPU with $5 \%$ CLOISITE Na+ 


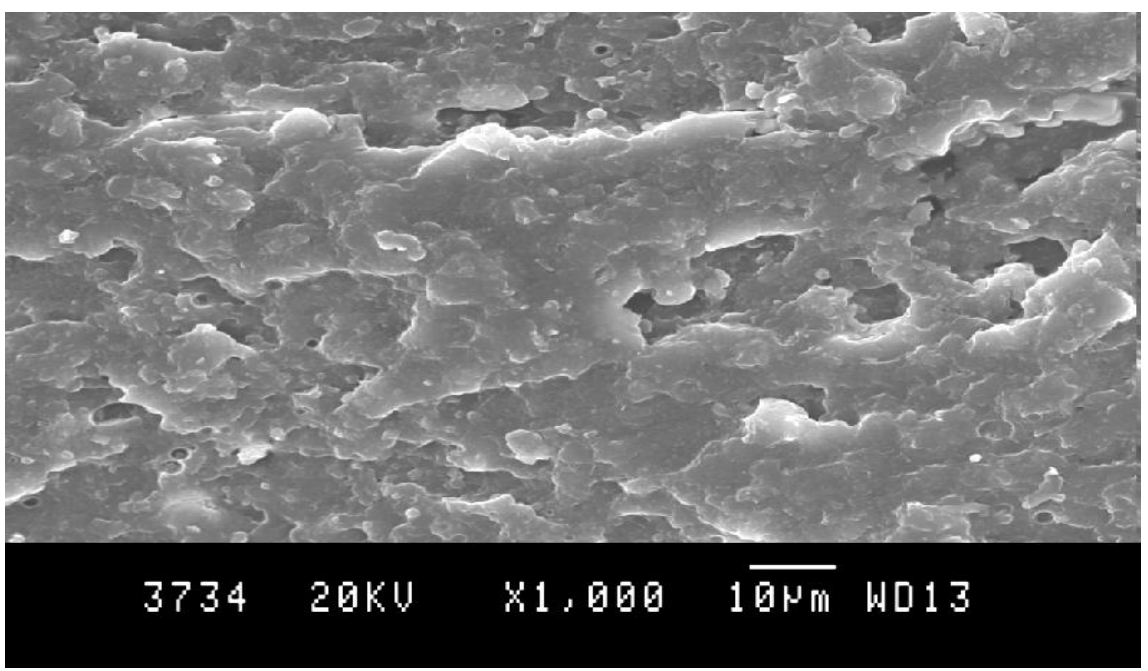

Figure 5a SEM of PA6 + TPU with 3\% CLOISITE 30B

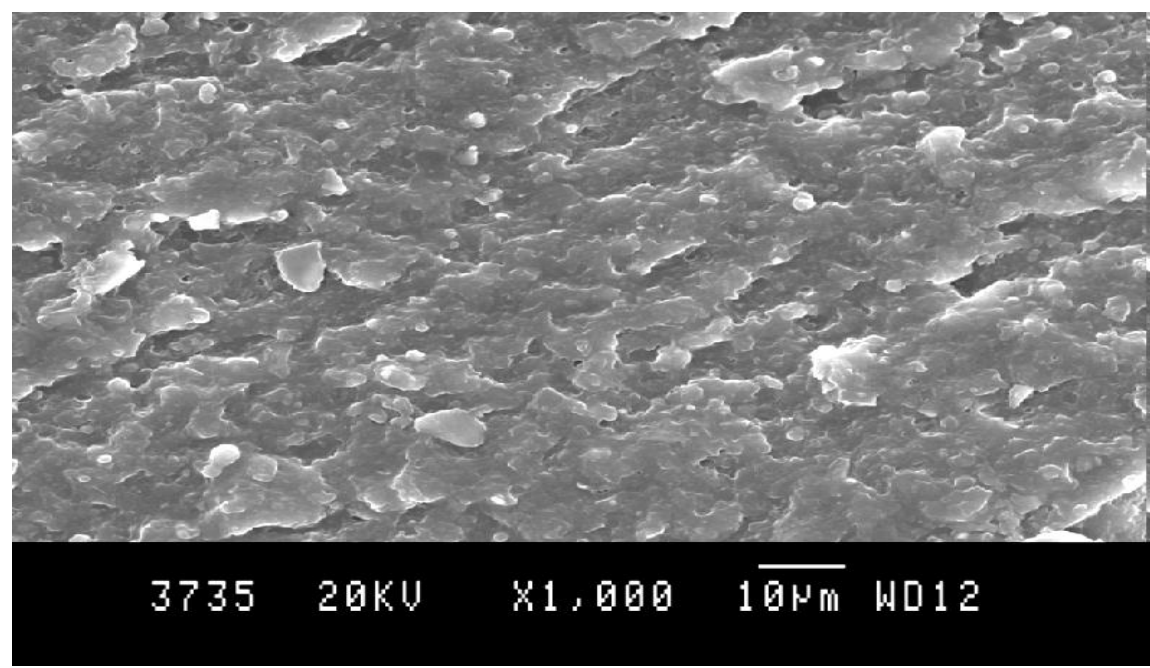

Figure 5b SEM of PA6 + TPU with 5\% CLOISITE 30B

case of $3 \%$ cloisite $\mathrm{Na}^{+}$, due to good dispersibility of the nano clay the impact strength was improved further than that of Nylon6-TPUR blend. Similarly, in the case of cloisite 30B, at 1\% concentration the toughness was further improved. But for 3\% \& 5\% it was litte lowered but not much varied from Nylon6-TPUR blend hence, the polymers were compatible with both type of nano clay fillers. DSC- Tg of TPU Rubber is about $-35^{\circ} \mathrm{C}$ due to polyols soft segments. We have also done this DSC below $30^{\circ} \mathrm{C}$ [Room temperature]. SEM is given also as evidence. TPU is dispersed well in Nylon 6 matrix which contains the nanoclays. Because TPUR is not remaining as rubber balls like structures as a separate phases in the SEM figures. Hence, TPUR in nylon 6nanoclay is a co-continuous phase and hence fully compatible.

\subsubsection{DSC [ Differential Scanning Calorimeter]}

Since we have used only one composition of Nylon6 with TPUR 85:15 wt\%, we have not used Rheological property $[\mathrm{MFI}]$ for knowing compatibility. However, we used the DSC, for knowing compatibility of this composition only. 


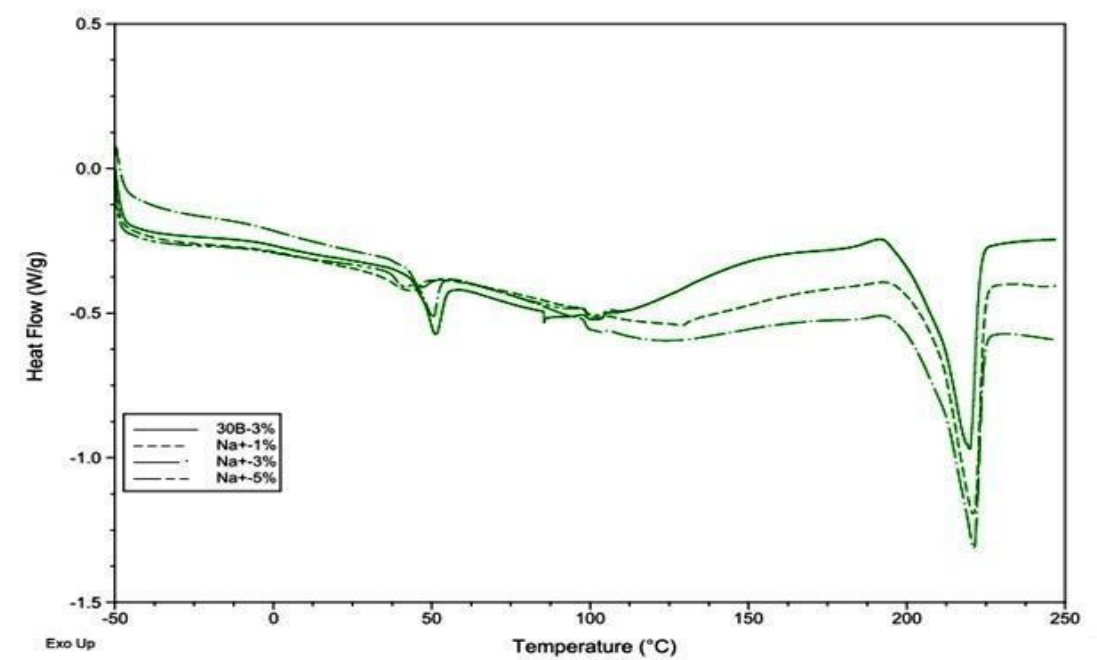

Figure 6 DSC thermograms of Nylon6-TPU blends with Nanoclays cloisite $\mathrm{Na}^{+}$and 30B

From DSC results we ascertained that, the Nylon6-TPUR is to be compatible and are like Polymer Alloys at this composition. The Tg of nylon6 was reported in the literature as 52-53 C [31,32] and dry nylon6 was found to be $60-65 \mathrm{C}$ by DMA analysis as reported by DSM Netherlands for Akulon K222D. The Tg of TPUR [Butane diol and Hexa methylene di isocyanate] was reported in the literature as $-39{ }^{\circ} \mathrm{C}$ to $-44{ }^{\circ} \mathrm{C}$ [33]. The peaks at 37.5 to $45{ }^{\circ} \mathrm{C}$ indicates that Nylon6 -TPUR [85:15 wt \%] is misible and compatible. Lik alloy in presence of nanoclay $\mathrm{Na}^{+} 5 \%$ and $1 \%$ [Fig 6]. The peaks are slightly at higher temp for $3 \% \mathrm{Na}^{+}$and $3 \% 30 \mathrm{~B}$ clay. However, the Polymers are compatible.

\subsubsection{X-RAY Diffraction}

The XRD were taken for all formulations. The XRD [Fig 7] shows the intercalation of CLOISITE 30B at $1 \%, 3 \%$ and 5\% clay incorporation. In the XRD diagram, the peaks have different 2 the values for the nanocomposites due to intercalation of the nanostructures. Hence, 2 the differs [greater] than that of Cloisite 30B. So The XRD is the clear indication of intercalation of clay platelets happening in PA6 and TPUR matrix.

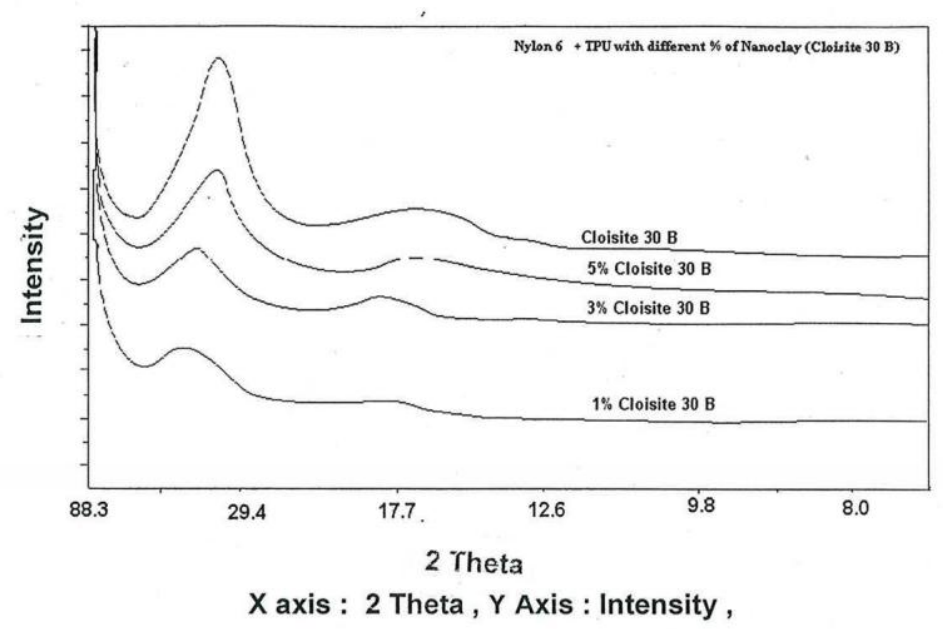

Figure 7 : XRD of Cloisite 30B , 1\% , 3\% and 5\% cloisite 30B filled Nylon6-TPUR blend

The nano filler is intercalated in the Nylon-6 matrix during melt blending before reaching the sixth zone. When TPUR was introduced in the sixth zone the nano particles may not be exfoliated much form nylon6 or partly again intercalated to the amorphous TPUR polymer segments. Hence the above trend may be observed. If further clay concentration will increased the tensile strength \& flexural modulus may increase but the impact 
strength will be drastically reduced due to saturation of the nanoclay concentration. Hence optimum nanoclay was used.

The unit for 2 theta is Degree. The $d$ spacing in cloisite 30B is $18.5 \AA$ [Amstrong] as reported by Southern clay Products Inc [USA]. Due to intercalation the peak positions were shifted in the Nano composites of Nylon6-TPUR when compared to 30B nanoclay the wave length of X-ray used in the equipment is not known. However, it may in the range of $0.02-100 \AA$ units. We have taken the XRD in the Wide Angle XRD Spectrum [WAXS] with 0-90 degree angle and may be with very high Voltage gradient.

\subsection{TGA [Thermo Gravimetric Analysis]}

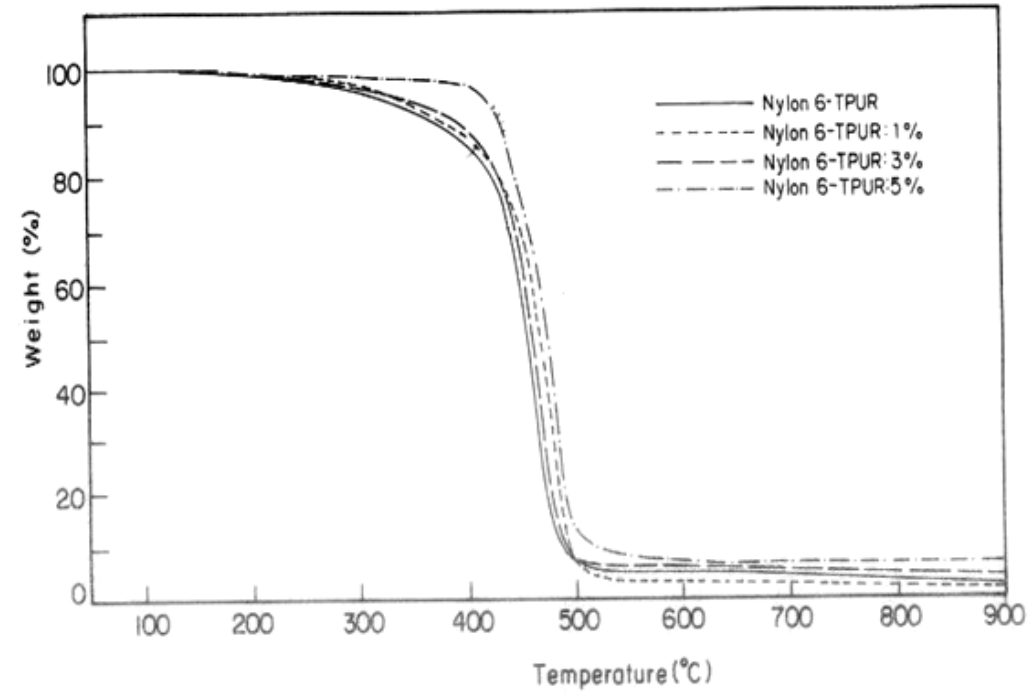

Figure 8 Thermo gravimetric analysis of Nylon 6-TPUR with Cloisite $\mathrm{Na}^{+}$

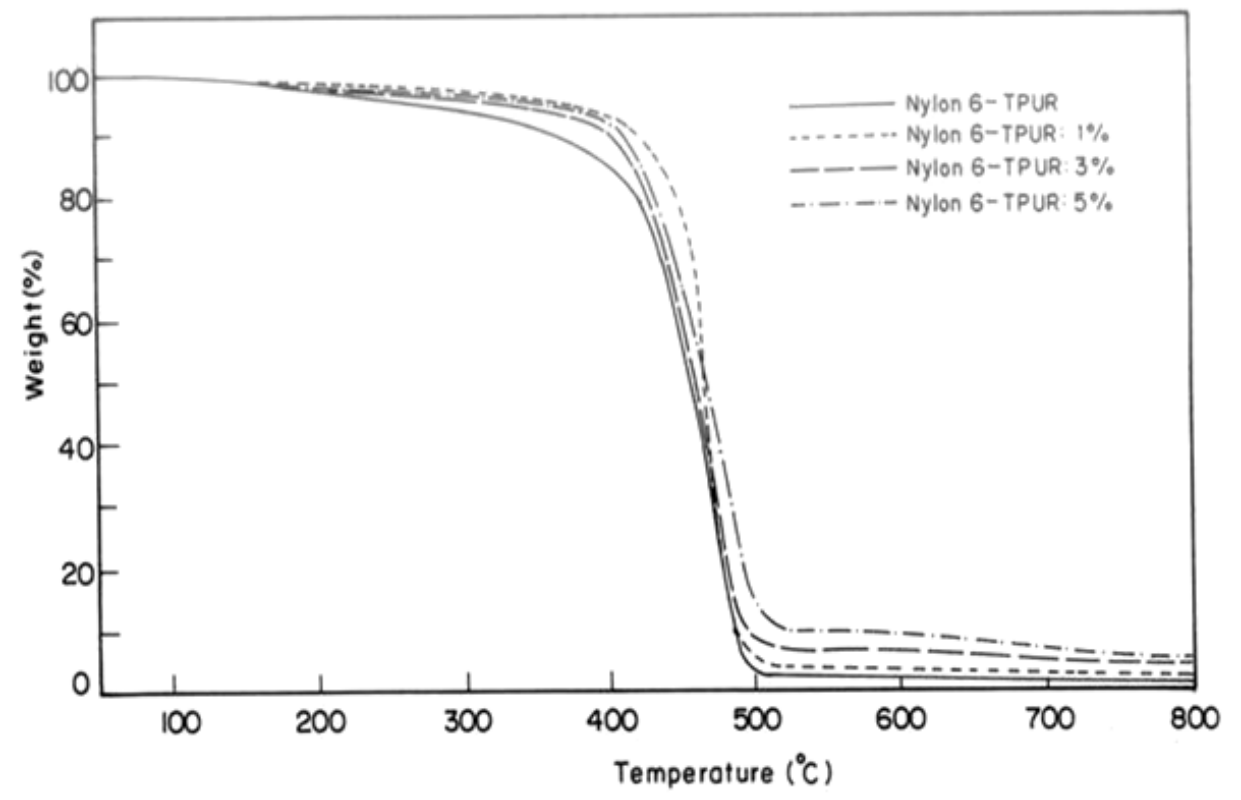

Figure 9 Thermo gravimetric analysis of Nylon 6-TPUR with Cloisite 30B

From the TGA study the thermal stability was evaluated. We have taken TGA. All the thermograms are included in figures 8 and 9 . The test results are also shown in the Table 5. The thermal stability was improved due to the inorganic nature of the nanoclays. Higher Thermal stability was achieved with $5 \% \mathrm{Na}^{+}$and with $1 \%$ 30B. In the case of cloisite 30B due to the organic nature of the 0020 modifiers the thermal stability is not much improved. Initially the $\mathrm{Na}^{+}$ions in presence of moisture may form $\mathrm{NaOH}$ which may catalyse the thermal degradation / depolymerization at a faster rate. Hence for Nylon 6-TPUR with $1 \%$ \& 3\% Na-MMT, the initial degradation temp is less than that of Nylon6-TPUR blend with 1\% cloisite 30B The thermal stability of the 
organoclay is determined by the thermal stability of the onium ion treatment. It is reported in the literature that the TGA curve for Cloisite ${ }^{\circledR} 20 \mathrm{~A}$ and Cloisite ${ }^{\circledR} 15 \mathrm{~A}$ show the onset of decomposition begins above $200^{\circ} \mathrm{C}$ for the onium ion [here $\mathrm{NH}_{4}^{+}$type] on montmorillonite. However, the onset temperature does not consider the kinetic of decomposition and do not have data on the kinetics of the onium ion decomposition. Taking into consideration of the thermal stability of the organoclay, extrusion is still an acceptable process to make many nanocomposites

Table 5 : Thermogravimetric Analysis of Nylon6/TPUR Blend with Nanofillers

\begin{tabular}{|c|c|c|c|c|c|}
\hline \multirow[t]{2}{*}{ Material } & \multicolumn{3}{|c|}{ Temperature ${ }^{\circ} \mathrm{C}$} & \multirow{2}{*}{$\begin{array}{l}\text { On set of } \\
\text { Degradation } \\
{ }^{\circ} \mathrm{C} \\
\end{array}$} & \multirow{2}{*}{$\begin{array}{c}\text { Weight } \\
\text { Remaining } \\
\%\end{array}$} \\
\hline & $\begin{array}{c}10 \% \\
\text { wt loss }\end{array}$ & $\begin{array}{c}50 \% \\
\text { wt loss }\end{array}$ & $\begin{array}{c}90 \% \\
\text { wt loss }\end{array}$ & & \\
\hline PA6 + TPUR & 370 & 460 & 490 & 390 & 90 \\
\hline $\begin{array}{l}\text { Cloisite } \mathrm{Na}^{+} \\
\text {PA6 + TPUR +1\% } \\
\text { PA6 + TPUR +3\% } \\
\text { PA6 + TPUR +5\% }\end{array}$ & $\begin{array}{l}370 \\
380 \\
425 \\
\end{array}$ & $\begin{array}{l}460 \\
460 \\
465 \\
\end{array}$ & $\begin{array}{l}490 \\
490 \\
525 \\
\end{array}$ & $\begin{array}{l}437 \\
406 \\
429 \\
\end{array}$ & $\begin{array}{l}92.2 \\
94.4 \\
99.9 \\
\end{array}$ \\
\hline $\begin{array}{l}\text { Cloisite 30B } \\
\text { PA6 + TPUR + } 1 \% \\
\text { PA6 + TPUR +3\% } \\
\text { PA6 + TPUR +5\% }\end{array}$ & $\begin{array}{l}430 \\
400 \\
415\end{array}$ & $\begin{array}{l}470 \\
465 \\
470\end{array}$ & $\begin{array}{l}480 \\
490 \\
510 \\
\end{array}$ & $\begin{array}{l}430 \\
400 \\
419 \\
\end{array}$ & $\begin{array}{l}90.0 \\
90.0 \\
93.6\end{array}$ \\
\hline
\end{tabular}

More details about the Thermal stability of modified nanoclays are given in the book [34]. Also in this book intercalation and exfoliation [dispersion] are explained at page 68-70 [35].

\subsection{Flammabilty}

The UL-94 vertical flammability test indicates that UL $94 \mathrm{~V}-2$ was obtained with $\mathrm{Na}^{+} \mathrm{Nano}$ clay. The TPUR in the Nylon 6 makes the material dripping and making the cotton to catch fire. Hence V-2 results were obtained. However, the test specimen ceases the fire within 10 seconds. But, in the case of $30 \mathrm{~B}$ clay the test specimens are burning upto the holding clamp with dripping and making the cotton to catch fire. The organic modifier may make the nanocomposites more flammable.

The flammability can be improved by the use of $\mathrm{Mg}[\mathrm{OH}]_{2}$ (in between silicate layers) or $\mathrm{Al}$ $[\mathrm{OH}]_{3}$. (ATH), flame retardants. It is reported that the MMT [Unmodified] is more thermally stable up to $600^{\circ} \mathrm{C}$ than O-MMT [Organically modified montmorillonite] nanoclays due to onium ions $\left[\mathrm{NH}_{4}^{+}\right.$] [27]. Hence, since thermal stability was better in MMT, the flame resisitance was better in $\mathrm{Na}^{+}$Nano clay.

The nylon 6 - TPUR [85:15 wt \%] blend will have optimum mechanical properties with better impact strength, lower water absorption and good electrical insulation properties. Both these polymers have polar functional groups, which may interact like allaphanate linkage [36] at normal temp and thermally labile at processing temperature and hence good compatibility will be present without any compatibilizer. However, the elastic modulus will be lowered. So, nano filler is used [1\%, 3\% \& 5\%] to improve the modulus along with good toughness. Hence, super tough materials can be made using nanoclays with nylon-TPUR Blends.

\section{Conclusion}

As Nano clay concentration increases, the tensile strength, tensile modulus, flexural strength and modulus were increasing. The elongation at break decreases. Optimum mechanical properties were obtained with 5\% Cloisite $\mathrm{Na}^{+}$and 5\% Cloisite 30B filled nylon6-TPUR blends i.e higher tensile strength and flexural modulus with medium impact strength than that of nylon6-TPUR blend. Generally the Cloisite $30 \mathrm{~B}$ provides higher tensile and flexural properties. $1 \%$ cloisite 30B shows highest impact strength. DSC thermograms and the SEM micro photographs shows the nylon6-TPUR blend is compatible and also in presence of the Nanofillers the nylon6-TPUR blends were compatible The XRD shows the intercalation of Cloisite $30 \mathrm{~B} \& \mathrm{Na}^{+}$ at $1 \%$, and $3 \%$. But at $5 \%$ clay incorporation it is not much intercalated. Because the peaks were shifted more for $1 \%$ and $3 \%$ than that of $5 \%$ filled cloisite 30 B.The Thermal stability were improved for both types of nano composites.

The closites $\mathrm{Na}^{+}$filled composites were having UL 94 V-2 But Cloisite 30B filled composites were not meeting the UL94 Vertical burning Standard. If further clay concentration will increased, the tensile strength $\&$ flexural modulus may increase but the impact strength will be drastically reduced. 


\section{Acknowledgement}

The nanoclays by the Connell Brothers Company India Ltd, Mumbai is greatly Acknowledged by the Authors. The help rendered by Mr N Sivapatham, Research scholar for twin screw compounding is also greatly Acknowledged.

[1]. Sinha S,Okamoto, Progress Polym Sci, 2003, 28, 1538

[2]. Fornes T D,Hunter DI, Paul DR, Polymer, 2004, 45, 2321

[3]. Maurizio Fermeglia, Margo Ferrone and Sabrina Prict Fluid Phase Equillibria ,2003, 212, 315

[4]. M. Muriel A Duabult and J L Halary Polym Int, 2007, 56, 214

[5]. Shaobo Xie, Shimin Zhang Huiju Liu, Guanming Chen,Meng Feng Hauili Qin Fosong Wang and Mingshu Yan, Polymer, 2005, 46,5417

[6]. K. Yang and R Ozisik, Polymer, 2006, 47, 2849

[7]. F Chavarria and D.R. Paul, Polymer, 2004, 45, 8501

[8]. In Yee Phang,Tian Xi Liu,Ashiq Mohamed, Kumari Pallathadka, Pramoda, Ling Chen, Lu chen, Shue Yin chow,Chaobin He, Xuehong Lu and Xiao HU, Polym Int, 2005, 54,456

[9]. Yimin Wang, Junpeng Gao, Yunqian Ma and Uday S Agarwal, Composites Part B Engg., 2006, 37,399

[10]. Young Wook Chang, Suksoo Kin and Young bin Kyung, Polym Int., 2005, 54, 348

[11]. P.J.Yoon, D.L. Hunter \& DR Paul, Polymer, 2003, 44, 5341

[12]. Ruo Wen Zong, Yuanttu, Shaofeng Wang and Lei Song, Polym Deg and Stability, 2004, 83, 423

[13]. S.M.Lai, H-C .Li and Y.C.Liao, Euro Polym J.,2007, .43,1660

[14]. Weigho Shao,Qi Wang and Hung Ma, Polym Int., 2005, 54, 336

[15]. Jr Hao Liaw Tony Yi H Such TAI -Sheng Tan Yeh Wang,And Shu-min Chiao Polym Int.,2007, 56, 2007, 1045

[16]. Liu X Wu Q, Macromol.Materi Eng, 2002, 287, 180

[17]. Sornia, Alexandra Garea Horia lovu, Stefania stoleriu and Geor geta Voicu, Polym Int., 2007, 56, 1106

[18]. Urko Gurmendi Jose Ignacio Eguiazababe and Jon Nazabal , Polym Int., 2006, 55,399

[19]. M Larrang E Lena Serrano Et al, Polym Int., 2007, 56, 1392

[20]. Kelnar I, J. Kotek, L.Kaprolkova B.S Munteam U, J. Appl.Polym Sci., 2005, 96, 288

[21]. Zhang M Liu Y, Zhang X, Gao J Huang F etal, Polym.,2002, 43, 5133

[22]. Szu-Hui Lim, Aravind Dasari, Zhong-zhen Yu ,Yiu-Wing Mai, Song Liu and Ming Shyan Yong Composites Sci \&Tech., 67, 2007,67

[23]. W. Dong, X-Zhang, Y.Liu, H.Gui Wang J Gao, Z Song, J Lai, F Huang and J Qiao, Polym Int.,2007, 56, 870

[24]. J A Brydson, Plastic Materials, Butterworth-Heinmann, $7^{\text {th }}$ Edition 2005, 784

[25]. K Palanivelu, P Sivaraman,S K Sharma and Sushil K Verma, International J Plastics Technology, 2003, 7, 133

[26]. Ivan Kelnar, Jakub Rotreki, Jiri Kotek apralkova, Polymer nternational, 2008, 59, 1281

[27]. Jin-Hae Chang \& Mu kyung Mun, Polymer International, 2007, 56, 57

[28]. Phang, Y, Tianxi Liu, Ashiq Mohamed, Kumari Palla Thadka, Lingchen, Lu Shen, Polymer International, 2005 , 54, 456

[29]. Ivan Kelnar, Ja Kub Rotreki, Jiru Kotek and Ludmila Kapral Kova, Polym Int, 2008, 57, 1281

[30]. Liu, Tx, Liu Zh Makx, Shen L Zeng Ky and He CB, Comp Sci Technology, 2003, 63, 331

[31]. J. Brandrup and E.H Immergut, Polymer Handbook, John Wiley \& Sons, New York, II edition, 1975, III-163

[32]. Premamoy Ghosh, Polymer Science and Technology-Plastics, Rubbers, blends \& composites, Tata McGraw Hill Pub Company Ltd, New Delhi, III edition, 2011, 281

[33]. J. Brandrup and E.H Immergut, Polymer Handbook, John Wiley \& Sons, New York, II edition, 1975, III-168

[34]. Vikas Mittal, "Optimization of Polymer Nano Composite Properties"Wiley VCH-Verlag GmbH \& Co, 2010, KGaH, Wein Heim P8

[35]. ibid P68.

[36]. J A Brydson, Plastic Materials, Butterworth-Heinmann, $7^{\text {th }}$ Edition 2005, 782 .. 